\title{
PRIMARY STUDENTS' MATHEMATICAL LITERACY: A CASE STUDY
}

\author{
Rooselyna Ekawati*1, Susanti ${ }^{2}$, Jian-Cheng Chen ${ }^{3}$ \\ ${ }^{1,2}$ Universitas Negeri Surabaya \\ ${ }^{3}$ National Taipei University of Education
}

\section{Article Info \\ Article history: \\ Received Nov 2, 2019 \\ Revised Feb 3, 2020 \\ Accepted Feb 11, 2020 \\ Keywords: \\ Indonesia, \\ Mathematical Literacy, \\ PISA like, \\ Primary Students}

\begin{abstract}
This paper analyses Indonesian primary students' Mathematical literacy in solving PISA like problems. The instruments were administered to 254 sixth graders from five different regions in Surabaya, Indonesia with various social background. There were three contents (quantity, Uncertainty and data, space and shape) and three level problems (High, Medium and Easy) used to develop Mathematics Literacy Test (MLT). Three students' categories (Good, Middle and Low) were established by cluster analysis methodology. The most students' challenge on MLT was space and shape as well as uncertainty and data's content problem. The description of profile of primary students' mathematical literacy related to MLT are worthy to suggest the design of learning lines for primary students to have more opportunity to learn and solve Mathematics literacy problem.
\end{abstract}

Copyright () 2020 IKIP Siliwangi. All rights reserved.

Corresponding Author:

Rooselyna Ekawati,

Department of Mathematics,

Universitas Negeri Surabaya

Kampus Unesa Ketintang,

Jl. Ketintang, Surabaya, East Java 60231, Indonesia.

Email: rooselynaekawati@unesa.ac.id

\section{How to Cite:}

Ekawati, R., Susanti, S., \& Chen, J. C. (2020). Primary students' mathematical literacy: a case study. Infinity, 9(1), 49-58.

\section{INTRODUCTION}

There has been increased attention to students' mathematical literacy nowadays and have widely admitted as one of interesting issues in mathematics education by many scholars both theoretically and practically. It is due to the need for everyone to have such ability to encounter todays complex problem Mathematics literacy becomes one focus on The Programme for International Student Assessment (PISA). The Organization for Economic Co-operation and Development's (OECD) programme for PISA and TIMSS have heightened international awareness of the value and significance of mathematical literacy. The document of PISA 2003 explained that mathematical literacy plays important roles in solving PISA problem as described by Hayat (2010). Mathematical literacy is an individual's capacity to formulate, employ, and interpret mathematics in a variety of contexts. It includes reasoning mathematically and using mathematical concepts, procedures, fact, and tools to describe, explain, and predict phenomena. It assists individuals to recognize the role that mathematics plays in the world and to make the well- 
founded judgments and decisions needed by constructive, engaged and reflective citizens, OECD (2014). There is a growing concern on literacy program in the national level such as Surabaya Indonesia. It starts to develop reading culture at school by lead students to read book 10 to 15 minutes before the lesson start. In addition to it, Mathematical literacy is as important as proficiency in reading and writing. Mathematics is so entwined with today's way of life that we cannot fully comprehend the information that surrounds us without a basic understanding of mathematical ideas (Ojose, 2011). These phenomena can influence the positive awareness of the needs of learners' mathematical literacy skills. Report of International assessment of the PISA Mathematics surveys showed that Indonesian students' performance has not shown satisfactory results which posited below the average score. In the period 2003-2009 almost 80\% of 15-years-olds students were only able to reach below level 2 out of 6 levels of questions examined (Widjaja, 2011). Moreover, on PISA survey 2009 almost all Indonesian students only reached level 3, whereas only $0.1 \%$ of Indonesian students reaching level 5 and 6 (Stacey, 2011). The report by Widjaja (2011) shared 15-years-olds students' performance. Therefore, Indonesia is admitted to be able to give chance to students to learn mathematics especially in solving PISA problems. However, there is a limited study of exploring primary students' mathematics literacy in more details.

Numerous studies have reported the assessment of the domain of mathematics literacy, for example Stacey (2011) reported the PISA view of Mathematical literacy in Indonesia which consider the PISA score. Furthermore, Wijaya, van den HeuvelPanhuizen, Doorman, \& Robitzsch (2014) pointed that Indonesian secondary students mostly experienced difficulties in the early stages of solving PISA tasks, namely understanding the meaning of a problem and transforming a word problem into an appropriate mathematical problem. In terms of in European countries, Höfer \& Beckmann (2009) discussed the supporting mathematical literacy which were applied in several schools in Denmark, Finland, Slovenia and Germany. The supporting model that delivered to those several European countries was believed to suit to the local situation. In order to have similar opportunity in supporting early learners' mathematical literacy in Indonesia, it needs a clearer picture of the current Indonesian students especially primary students' mathematical literacy. In this study, we aimed at comprehensively describing the profile of Indonesian primary students' mathematical literacy in solving Mathematics Problem. In order to put forward the operationally reliable measure, we started with reviewing several literatures about mathematical literacy and afterwards developing framework for instrument used as well as undertaking detailed item analysis.

\subsection{Mathematical Literacy}

There are several definition of mathematical literacy from PISA 2003 to PISA 2015. Based on definition of PISA 2003, PISA 2012 elaborated mathematical literacy as 'individual's capacity to recognize, do and use mathematics in a variety of contexts, and to identify the role that mathematics plays in the world. More mathematically literate individuals are better able to use mathematics and mathematical tools to describe, model, explain and predict phenomena, in order to make the well-founded judgements and decision required by constructive, engaged and reflective citizens (OECD, 2010). Based on that definition, mathematical literacy is close related to problem in daily life that can be solved. The important aspect of mathematical literacy is considering problem solving in variety of context. The defining feature of mathematical literacy is that it has to do with thinking mathematically while simultaneously thinking about the context in which the mathematics is being used (Stacey \& Turner, 2015). 
There are three connected aspects in mathematical literacy in OECD (2013) namely process, content and context. The categories of mathematical content are Quantity, Uncertainty \& data, Change \& Relationship; Space \& Shape. Furthermore, real world context categories consist of Personal, Societal, Occupational and Scientific. Dealing with PISA problem, it necessarily involves mathematical thought and action that has three components such as Mathematical concepts, knowledge and skills. The process of mathematical literacy begins with identifying problem in context and formulating the problem mathematically based on the concepts and relationship inherent in the problem. Afterwards, the process of employing, interpreting as well as evaluating are considered. Concepts and procedures, which are the backbone of traditional mathematical curriculum, are not the main focus of the PISA curricular framework (Sáenz, 2009). Therefore, through PISA problem, students need knowledge that can be productively used to problem situations. Figure 1 showed the mathematical literacy in practice framework that described in OECD (2010).

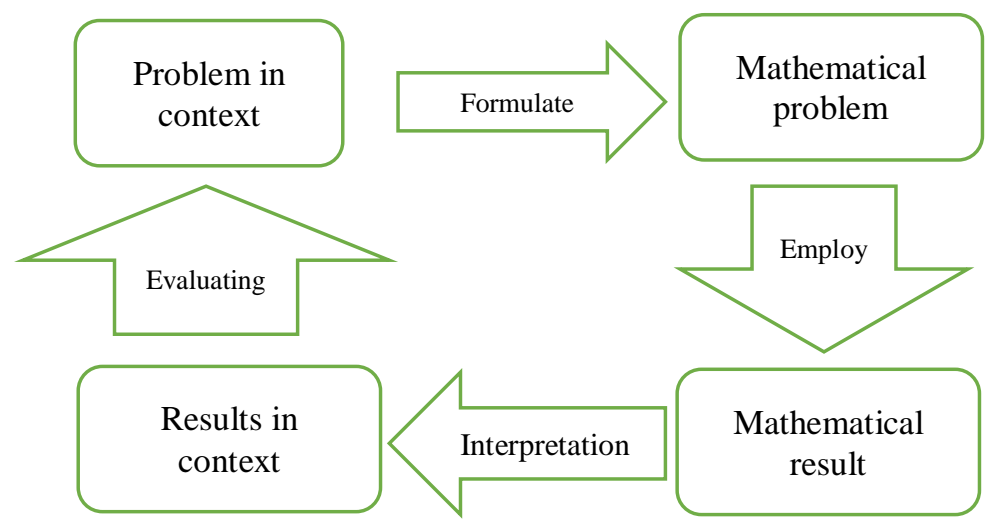

Figure 1. Mathematical Literacy in practice (OECD, 2010)

\section{METHOD}

The participants in this study were sixth grade primary students. We delivered the instrument to 254 sixth graders from five region of Surabaya, East Java Indonesia with various social and economic background. Students' participants were asked to complete their identitiy and worked on the Mathematics Literacy Tasks (MLT)

\section{Phase 1: Developing Mathematics Literacy Tasks}

To document primary students' mathematical literacy, we developed paper pencil test instrument called Mathematics Literacy Tasks (MLT). The characteristics of MLT satisfies the PISA framework. The developing of MLT item test involves two phases such as (1) defining conceptions of item components and (2) developing and validating test instrument with pilot study. The first phase: defining conceptions of item components. In this phase, we consider the PISA framework and considering Context, Content, Process as well as level of problem. For the validating test instrument, we explore the reliability of instrument. 


\section{Phase 2: Developing and Validating the Test Instrument.}

The MLT went to multiple stages of revision before applied to larger number of participants. Discussion with mathematics education experts and piloting test among 53 sixth graders in 90 minutes were executed and considered as the process of validating process of the test instrument. The comprehensive coding scheme for MLT were coded as "correct=score 1" and "incorrect=score 0 ".

\section{Cluster Analysis}

In this study, cluster analysis was applied to the data mainly concerning students' responses to the MLT items. "Cluster analysis is required to divide a set of observations into groups or clusters in such a way that most pairs of observations that are placed in the same group are more similar to each other than are pairs of observations that are placed into different clusters (Vidal, Ma, \& Sastry, 2016)". Cluster Analysis based on factor score was done to get the pattern description from students' responses. By the result of cluster analysis, primary students' mathematics literacy can be determined. In addition, we explored students' challenges in solving MLT with regard Context, Content, Process as well as level of problem. Besides, the interview were done to explore more on the picture of students challenges and difficulties.

\section{RESULTS AND DISCUSSION}

\subsection{Results}

The Mathematics Literacy Task (MLT) consist of 15 developed items, and the reliability result of Cronbach's alpha of the piloted MLT was 0.55 for 53 students' respondents. Significance level 5\% is 0.2706 . With criteria of decision of Cronbach's alpha $=0.550$ which is greater than $r$ table then it considered reliable items. Table 1 showed the description of MLT after some revision by considering pilot study result.

Table 1. Description of MLT

\begin{tabular}{|c|c|c|c|c|c|}
\hline No & Context & Content & Process & Level & Description \\
\hline 1 & Personal & Quantity & Employ & 1 & $\begin{array}{l}\text { Sorting decimal } \\
\text { contextual problem }\end{array}$ \\
\hline 2 & Personal & Quantity & Interpret & 2 & $\begin{array}{l}\text { Using proportional } \\
\text { reasoning for estimating the } \\
\text { length of a thing. }\end{array}$ \\
\hline 3 & Personal & Uncertainty and data & Interpret & 3 & $\begin{array}{l}\text { Interpreting a statement } \\
\text { related to average }\end{array}$ \\
\hline & & & & & To explore its truth. \\
\hline 4 & The work & Space and shape & Interpret & 2 & $\begin{array}{l}\text { Interpreting the form from } \\
\text { above of a pile of cubes. }\end{array}$ \\
\hline 5 & Personal & Quantity & Employ & 3 & $\begin{array}{l}\text { Determining quantity of an } \\
\text { object within contextual } \\
\text { problem. }\end{array}$ \\
\hline 6 & Personal & Uncertainty and data & Interpret & 2 & $\begin{array}{l}\text { Interpreting data that } \\
\text { showed in bar diagram }\end{array}$ \\
\hline
\end{tabular}




\begin{tabular}{|c|c|c|c|c|c|}
\hline No & Context & Content & Process & Level & Description \\
\hline 7 & Social & Space and shape & Interpret & 4 & $\begin{array}{l}\text { Interpreting visual form of } \\
\text { object with given its volume }\end{array}$ \\
\hline 8 & Social & Quantity & Interpret & 5 & $\begin{array}{l}\text { Examining the truth of } \\
\text { statement that related to } \\
\text { percentage concept }\end{array}$ \\
\hline 9 & Personal & Space and shape & Formulate & 5 & $\begin{array}{l}\text { Formulate a simple } \\
\text { mathematics model that } \\
\text { related to concept of pattern }\end{array}$ \\
\hline 10 & Scientific & Quantity & Employ & 3 & $\begin{array}{l}\text { Using mathematics' rule that } \\
\text { presented in contextual } \\
\text { problem. }\end{array}$ \\
\hline 11 & Personal & Space and shape & Interpret & 4 & $\begin{array}{l}\text { Drawing cubes' net based on } \\
\text { the cube's side }\end{array}$ \\
\hline 12 & The work & Space and shape & Intepret & 6 & $\begin{array}{l}\text { Interpret the plane based on } \\
\text { given perimeter. }\end{array}$ \\
\hline
\end{tabular}

There are 6 levels of Mathematical literacy problems given to students in this study. Three problems were categorized in 'High' level problems due to those are in level 5 and 6. Five problems were in the level 3 and 4 that categorized in 'Medium' level problem. Furthermore, four problems are categorized in 'Easy' level problem. Furthermore, the detailed means and standard deviations of MLT items obtained from the factor analysis process are shown in Table 2.

Table 2. Description of Statistics of the data

\begin{tabular}{cccc}
\hline $\begin{array}{c}\text { Mathematics } \\
\text { Literacy Tasks }\end{array}$ & Number of Samples & Mean & Standard Deviation \\
\hline MLT1 & 254 & 0.3386 & 0.47416 \\
MLT2 & 254 & 0.5827 & 0.49409 \\
MLT3 & 254 & 0.0630 & 0.24343 \\
MLT4 & 254 & 0.6260 & 0.48482 \\
MLT5 & 254 & 0.4173 & 0.49409 \\
MLT6 & 254 & 0.7717 & 0.42060 \\
MLT7 & 254 & 0.5248 & 0.46792 \\
MLT8 & 254 & 0.1992 & 0.35397 \\
MLT9 & 254 & 0.0409 & 0.15647 \\
MLT10 & 254 & 0.4551 & 0.48742 \\
MLT11 & 254 & 0.0157 & 0.12474 \\
MLT12 & 254 & 0.2087 & 0.40715 \\
\hline
\end{tabular}


As shown in Table 2, the maximum standard deviation of the MLT items were around 0.4 that indicated the dispersion of the data point tended to be close to the mean and considered as normal data.

\section{Cluster Analysis}

In this study, cluster analysis was applied to the data mainly concerning students' responses to the items. Cluster analysis based on factor score was done to get pattern of students' responses. There are three clusters categories to group the students in each school from five region of Surabaya who responded to the items in similar ways so that the cluster could be obtained. The three groups G1, G2 and G3 could be interpreted as students with "Good", "Middle", or "Low" students' mathematical literacy, respectively. Table 3 showed students' Mathematical literacy from five region of Surabaya, East Java, Indonesia.

Table 3. The level of Primary students' Mathematical Literacy

\begin{tabular}{clccc}
\hline \multirow{2}{*}{ No. } & Schools' region & Good & Middle & Low \\
\cline { 3 - 5 } & & $21.6 \%$ & $43.14 \%$ & $35.26 \%$ \\
\hline 1. & Centre Region & $9.5 \%$ & $40.5 \%$ & $50 \%$ \\
2. & East Region & $17 \%$ & $28.8 \%$ & $54.2 \%$ \\
3. & South Region & $36 \%$ & $62 \%$ & $2 \%$ \\
4. & West Region & $35.6 \%$ & $47.4 \%$ & $17 \%$ \\
5. & North Region & & & \\
\hline
\end{tabular}

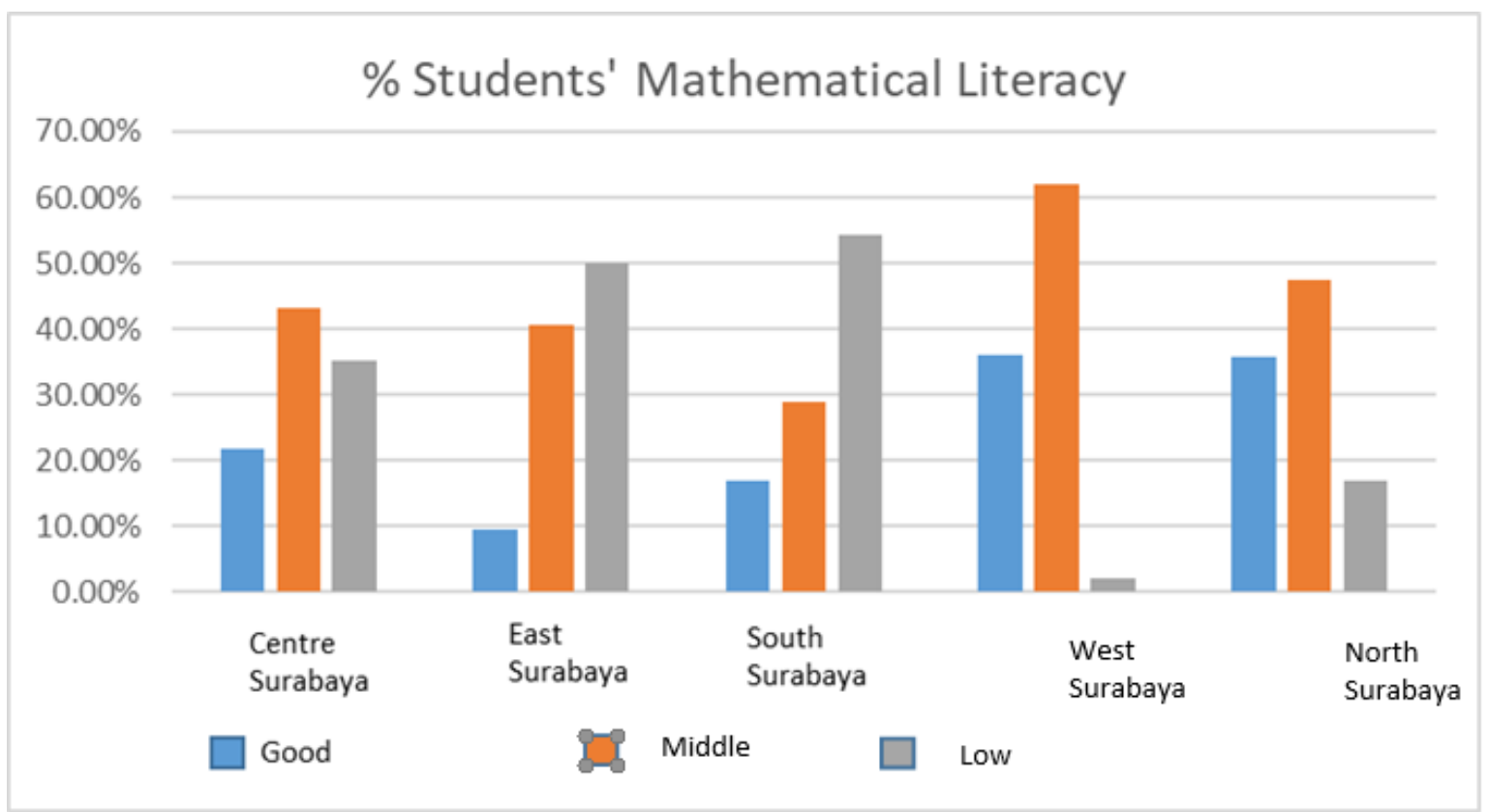

Figure 2. Students' Mathematical Literacy Level

Based on data above (Figure 2), in general, most students were in the Middle categories of students in solving Mathematical literacy problem. But in two regions, it 
shows students were in Low category. In addition, with regard to the level of MLT problem, students' performance (mean score of item in each problem's categories) can be drawn in Figure 3.

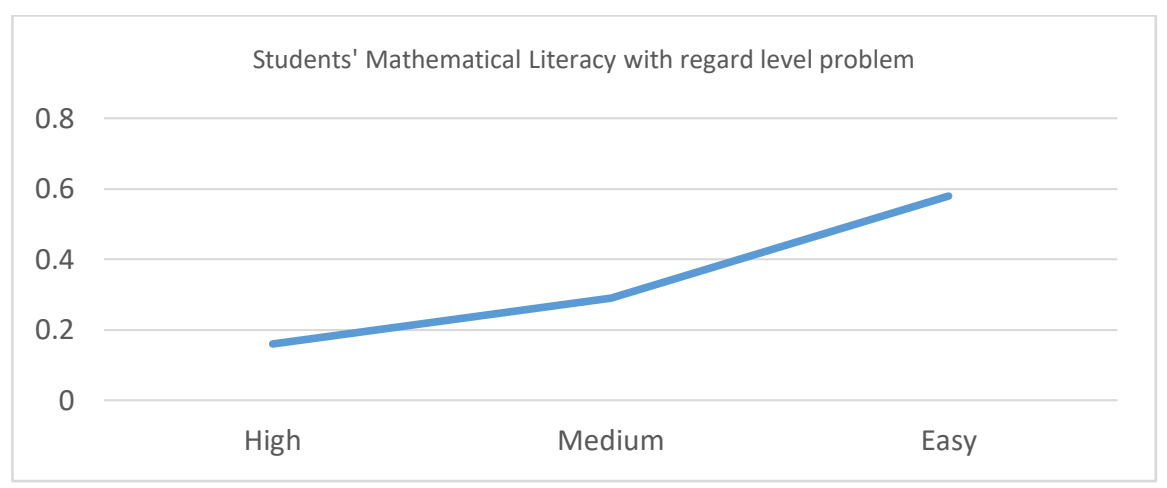

Figure 3. Students' performance based on level of MLT Problem

The data shows that the average score for the easy level problem is less than 0.7 and for the High level, the average score is less than 0.22. It can be determined that in general, students need more opportunity to learn and get used to solve literacy problem. Although students could attain high average score for easy problem, most students need more opportunity to learn about decimal fraction within contextual problem. They have difficulties in determining place value in decimal as well as in understanding the contextual problem given. Furthermore, within all medium level problems, problem of Statistics and Geometry are more demanding than other. Most students consider have challenge in solving problem related to "Mean, Median and Modus".

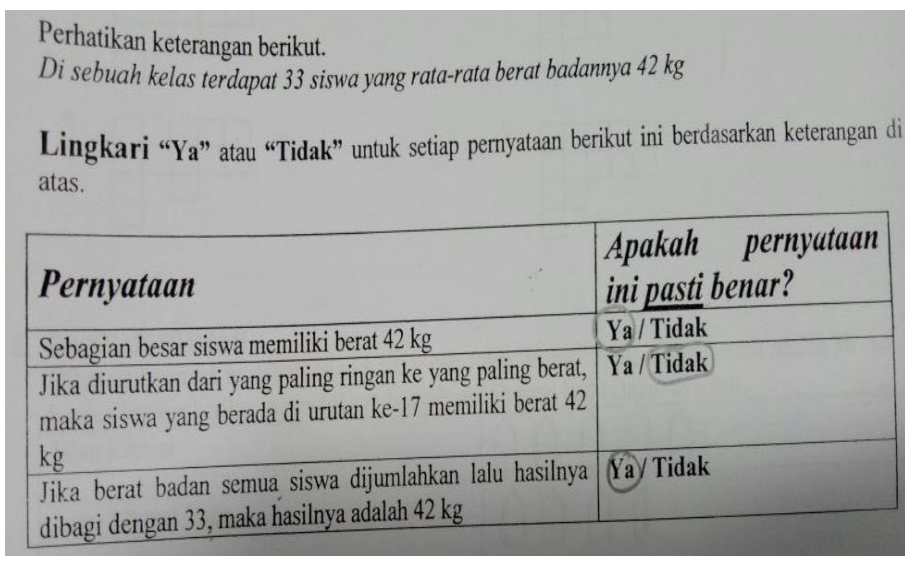

\begin{tabular}{l} 
Pay attention on the statement below \\
In a classroom, there are 33 students with the average \\
weight is $42 \mathrm{~kg}$ \\
$\begin{array}{l}\text { Circle "Yes" or "No" for every statement below based } \\
\text { on the statement above }\end{array}$ \\
\begin{tabular}{|l|l|}
\hline Statements & $\begin{array}{l}\text { Is the statement } \\
\text { below correct? }\end{array}$ \\
\hline Most students has weight $42 \mathrm{~kg}$ & Yes/No \\
\hline If we make an order from the & Yes/No \\
\hline $\begin{array}{l}\text { If we sum up all the students' } \\
\text { weight and the result is divided } \\
\text { by } 33, \text { the result is } 42 \mathrm{~kg}\end{array}$ & Yes/No \\
\hline
\end{tabular} \\
\hline
\end{tabular}

Figure 4. MLT problem \& a student' response on Uncertainty \& Data

Figure 4 shows a problem on content Uncertainty and Data in which students are asked to determine the meaning of the given statement. Student response that Mean can be described as the average of students' weight (the total of weight divided by the number of students). However, He also considered that the Mean can be interpreted as 'Most students has weight $42 \mathrm{~kg}$ ' which can be determined as Mode. In addition, some challenges were found by students in Space and Shape content problem. Figure 2 shows a MLT problem on Space and Shape. 


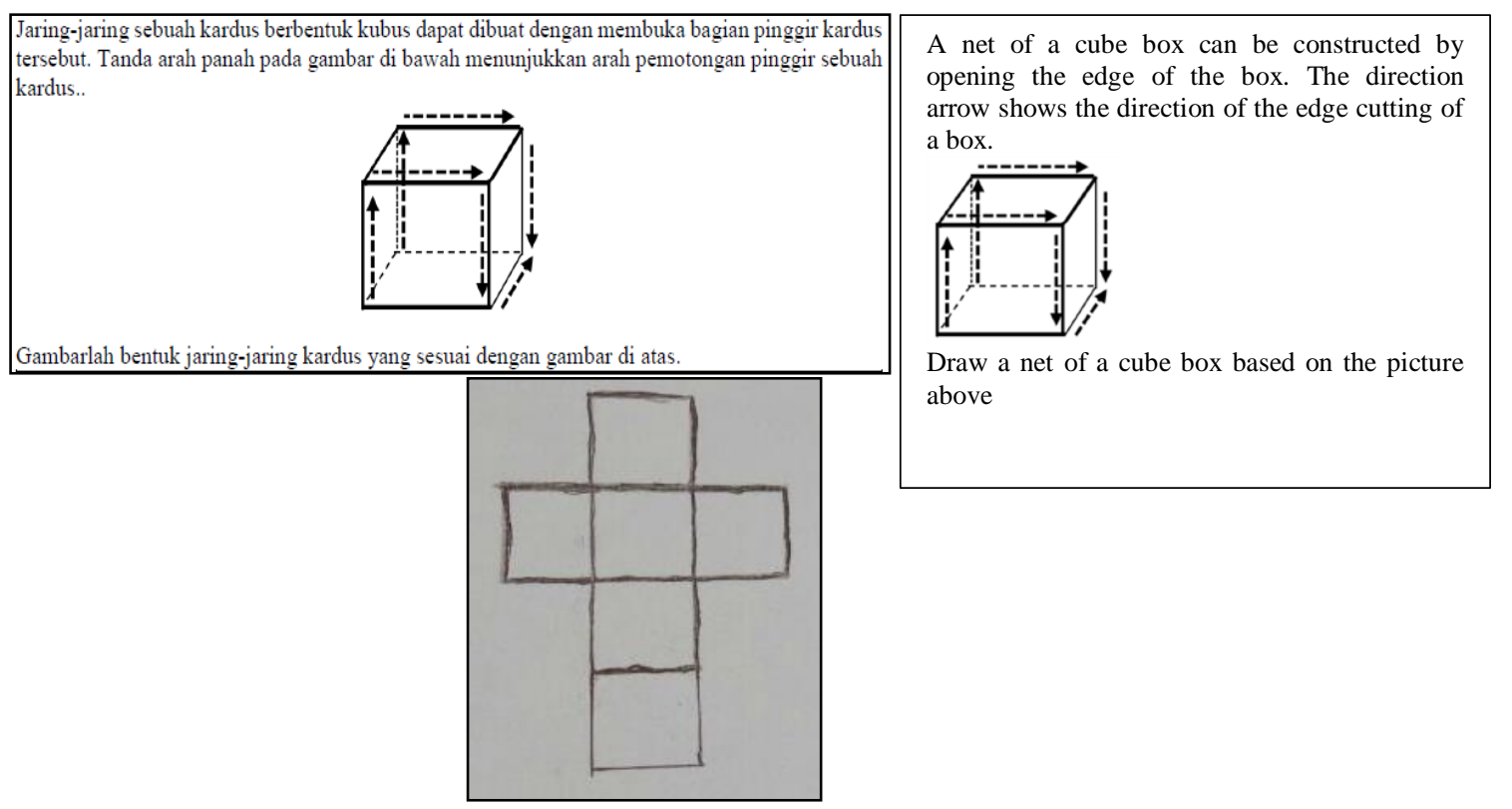

Figure 5. Space and shape content problem and most student's response

There were only $1.6 \%$ students could answer the problem of Figure 5 properly. Students mention that they found difficulty in following the cutting direction and draw the net of cube that they familiar with. By this, it can be considered that they have difficulty in making translation between $3 \mathrm{D}$ objects and $2 \mathrm{D}$ nets.

\subsection{Discussion}

The result of quantitavive analysis of 254 students' responses on paper and pencil Mathematics Literacy Test showed that most students were in Middle and Low clusters. In terms of Mathematics Literacy Test problems, students performed best in determining graphical representation of content uncertainty and data that considered as Easy Level problem. This was due to they experienced about this lesson at school based on the document of curriculum. However, students faced challenges in higher level problem on content uncertainty and data. They had misunderstanding the concept of Mean, Median and Mode. They were asked to determine the statistical statements given with the context of weight. The problem regards the students' mathematical literacy that also influenced by logical reasoning as also considered by Ni'mah, Junaedi, \& Mariani (2017). Furthermore, most students fail in level 3 of Statistical Literacy at school by Watson (2003) namely Inconsistent Understanding. They could not engage with the context given and interpret the statistics incorrectly. For instance, students interpreted the average of students' weight as mode and median of the data of weight. This might happen since the texbook is only cover the data representation and not yet pointed to central tendency. Besides, the most challenging problems faced by students are the shape and space content's problem. Students need more opportunity to understand properties of objects and their relative positions in space and shapes. In other words, students are required to get more understanding the relationship between space and shape (Visual representation) and includes understanding how three-dimensional objects can be represented in two dimensions (Ojose, 2011). Several research result showed that students have great difficulties in conceptualising the translation of two different representation modes (3D and 2D) (Gutiérrez, 1992; Ben-Chaim, Lappan, \& Houang, 1989). This phenomena happen 
since the contruction of $2 \mathrm{D}$ nets need mental processes that students might not have. It needs an activity for students to utilize drawing 3D objects convention to avoid the misread drawing. Overall, primary students need more opportunity to learn and get used to the Mathematics literacy problems. To be more specific, the space and shape content and uncertainty and data contents were two demanding contents for primary students.

\section{CONCLUSION}

This study finds that Indonesian Students were able to work on content uncertainty and data problem. However, the most challenging problem they faced were shape and space contents' problem. In addition, a comprehensive overview of students' Mathematics literacy is essentially needed in future studies to develop effective Hypothetical Mathematics Learning Trajectory that support students' Mathematics Literacy.

\section{REFERENCES}

Ben-Chaim, D., Lappan, G., \& Houang, R. T. (1989). Adolescents' ability to communicate spatial information: Analyzing and effecting students' performance. Educational Studies in Mathematics, 20(2), 121-146. https://doi.org/10.1007/BF00579459

Gutiérrez, Á. (1992). Exploring the links between Van Hiele Levels and 3-dimensional geometry. Structural Topology 1992 núm 18.

Hayat, B. (2010). Literacy of our youngsters: results and restraints from PISA. International Journal of Education, 5(1), 1-16.

Höfer, T., \& Beckmann, A. (2009). Supporting mathematical literacy: examples from a cross-curricular project. ZDM, 41(1-2), 223-230. https://doi.org/10.1007/s11858008-0117-9

Ni'mah, L., Junaedi, I., \& Mariani, S. (2017). Mathematical literacy's vocational students based on logical and numerical reasoning. Infinity Journal, 6(2), 95-110. https://doi.org/10.22460/infinity.v6i2.p95-110

Ojose, B. (2011). Mathematics literacy: Are we able to put the mathematics we learn into everyday use. Journal of Mathematics Education, 4(1), 89-100.

OECD. (2010). PISA 2012 Mathematics Framework. http://www.oecd.org/pisa/pisaproducts/46961598.pdf

OECD. (2013). PISA 2012 result in focus: What 15-year-olds know and what they can do with what they know. http://www.oecd.org/pisa/keyfindings/pisa-2012-resultsoverview.pdf

OECD. (2014). PISA 2012 results: What students know and can do student performance in mathematics, reading and science. Volume I. Paris: OECD Publishing.

Stacey, K. (2011). The PISA view of mathematical literacy in Indonesia. Journal on Mathematics Education, 2(2), 95-126. https://doi.org/10.22342/jme.2.2.746.95-126

Stacey, K., \& Turner, R. (2015). The evolution and key concepts of the PISA mathematics frameworks. In Assessing mathematical literacy, 5-33. https://doi.org/10.1007/9783-319-10121-7_1 
Sáenz, C. (2009). The role of contextual, conceptual and procedural knowledge in activating mathematical competencies (PISA). Educational Studies in Mathematics, 71(2), 123-143. https://doi.org/10.1007/s10649-008-9167-8

Vidal, R., Ma, Y., \& Sastry, S. S. (2016). Principal component analysis. In Generalized principal component analysis, 25-62. Springer, New York, NY. https://doi.org/10.1007/978-0-387-87811-9_2

Watson, J. M. (2003): Statistical Literacy at the school level: What should students know and do? In Bulletin of the International Statistical Institute 54th Session Proceedings Berlin 2003, (Volume LX, Book 2, Invited Papers, Topic 49, pp. 6871)

Widjaja, W. (2011). Towards mathematical literacy in the 21st century: perspectives from Indonesia. Southeast Asian mathematics education journal, 1(1), 75-84.

Wijaya, A., van den Heuvel-Panhuizen, M., Doorman, M., \& Robitzsch, A. (2014). Difficulties in solving context-based PISA mathematics tasks: An analysis of students' errors. The Mathematics Enthusiast, 11(3), 555-584. 